Bài báo khoa học

\title{
Ửng dụng số liệu ảnh mây vệ tinh Himawari trong dụ̣ báo và cảnh báo mưa dông cho khu vực Đồng bằng sông Cửu Long
}

\author{
Trần Thành Công ${ }^{1}$, Lê Ngọc Quyền ${ }^{1}$, Nguyễn Minh Giám ${ }^{1}$, Lê Đình Quyết ${ }^{1}$ \\ ${ }^{1}$ Đài Khí tượng Thủy văn khu vực Nam Bộ; congtt@gmail.com, quyentccb@gmail.com, \\ nmg@kttvnb.vn, quyet.le74@gmail.com \\ * Tác giả liên hệ: congtt@gmail.com; Tel.: +84-989012367
}

Ban Biên tập nhận bài: 05/9/2020; Ngày phản biện xong: 07/10/2020; Ngày đăng bài: $25 / 11 / 2020$

Tóm tắt: Vệ tinh Himawari 8 là thế hệ vệ tinh mới nhất của Nhật Bản, bao gồm 16 kênh phổ. Việc phân tích các kênh phổ mang lại nhiều thông tin phục vụ cho công tác phân tích, dự báo, cảnh báo mưa-dông. Nghiên cứu này trình bày kêt quả nghiên cứu xây dựng công cụ trợ giúp công tác cảnh báo, dự báo mưa-dông cho khu vực Đồng bằng sông Cửu Long (ĐBSCL). Các tiện ích được tích hợp trong công cụ sử dụng nguồn số liệu 16 kênh phổ ảnh vệ tinh Himawari phân tích, tính toán: phân loại mây $(\mathrm{Ci}, \mathrm{Sc}, \mathrm{St}, \mathrm{Cu}, \mathrm{Cb} .$.$) , xác định nhiệt độ$ và độ cao đỉnh mây, xác định vùng mây dông, xác định vùng mây có khả năng sinh mưa, tính toán sự di chuyển của các khối mây $\mathrm{Cb}$. Công cụ cũng tính toán các số liệu phân tích và dự báo cho các vùng địa lý (đơn vị hành chính), đồng thời cung cấp tiện ích chuyển phát thông tin cảnh báo, dự báo thời hạn đến $6 \mathrm{~h}$ một cách nhanh chóng và hiệu quả nhất.

Từ khóa: Ảnh mây; Mưa; Dông; Himawari; Dự báo; Cảnh báo.

\section{1. Đặt vấn đề}

Mưa-dông là hiện tượng thời tiết điển hình, có ảnh hưởng rất lớn đến các hoạt động kinh tế-xã hội, sinh hoạt của con người. Với khu vực Đồng Bằng Sông Cửu Long (ĐBSCL) mưa vừa đem lại nguồn nguồn nước dồi dào cho phát triển nông nghiệp, thủy sản, vừa là nguyên nhân gây ra ngập lụt ảnh hưởng tiêu cực đến phát triển kinh tế xã hội và đời sống sinh hoạt của người dân. Do vậy công tác dự báo, cảnh báo mưa-dông khu vực ĐBSCL đóng vai trò rất quan trọng trong việc tăng cường mặt ảnh hưởng tích cực của mưa-dông và giảm thiểu các thiệt hại mà mưa-dông có thể gây ra.

Hiện nay, trên thế giới dữ liệu vệ tinh Himawari-8 được sử dụng khá rộng rãi trong dự báo thời tiết, đặc biệt là một số các hiện tượng thời tiết nguy hiểm như dự báo bão, mưa, dông. Vệ tinh Himawari là thế hệ vệ tinh mới nhất của Nhật Bản, bao gồm 16 kênh phổ trong đó có 3 kênh ở dải thị phổ là đỏ, xanh lá và xanh da trời có thể kết hợp với nhau tạo thành ảnh với màu tự nhiên tương đương với nhận biết từ mắt người. Chi tiết các kênh phổ được đưa ra trong hình 1. Độ phân giải không gian của các kênh phổ là $2 \mathrm{~km} \mathrm{x} 2 \mathrm{~km}$ đối với các kênh từ kênh 5 đến kênh 16. Các kênh thị phổ và cận thị phổ có độ phân giải $1 \mathrm{~km} \times 1 \mathrm{~km}$, riêng kênh thị phổ thứ 3 (VS) có độ phân giải tinh nhất, $0,5 \mathrm{~km} \times 0,5 \mathrm{~km}$.

Các kênh phổ từ 4 đến 6 là các kênh cận hồng ngoại.

Các kênh phổ từ 7 đến 16 là các kênh nằm trong dải hồng ngoại, trong đó kênh 7 (IR4) dùng để theo dõi sương mù và các đám cháy rừng. Các kênh 8 đến 10 là các kênh dùng để 
theo dõi hơi nước trong khí quyển tương ứng với các tầng thấp, tầng trung và tầng cao của khí quyển.

Kênh 11 dùng để theo dõi khí $\mathrm{SO}_{2}$ trong khí quyển, kênh 12 theo dõi ozone, trong khi kênh 16 theo dõi khí Cacbonic.

\begin{tabular}{|c|c|c|c|c|c|}
\hline \multicolumn{3}{|r|}{ Kênh } & \multirow{2}{*}{ 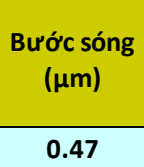 } & \multirow{3}{*}{$\begin{array}{c}\begin{array}{c}\text { Độ phân } \\
\text { giải } \\
(\mathbf{k m})\end{array} \\
1\end{array}$} & ứng dụng \\
\hline 1 & V1 & \multirow{3}{*}{ VIS } & & & Thảm thực vật, Sol khí \\
\hline 2 & $\mathrm{~V} 2$ & & 0.51 & & Thảm thực vật, Sol khí \\
\hline 3 & VS & & 0.64 & 0.5 & Thảm thực vật, mây tầng thấp, sương mù \\
\hline 4 & N1 & \multirow{3}{*}{ NIR } & 0.86 & 1 & Thảm thực vật, Sol khí \\
\hline 5 & $\mathrm{~N} 2$ & & 1.6 & \multirow{12}{*}{2} & Trạng thái mây \\
\hline 6 & N3 & & 2.3 & & Kích thước hạt \\
\hline 7 & 14 & SWIR & 3.9 & & Mây tầng thấp, sương mù, cháy rừng \\
\hline 8 & WV & \multirow{3}{*}{$\begin{array}{l}\text { Water } \\
\text { Vapor }\end{array}$} & 6.2 & & Lượng ẩm tầng trung và tầng cao \\
\hline 9 & W2 & & 6.9 & & Lượng ẩm tầng trung \\
\hline 10 & W3 & & 7.3 & & Lượng ẩm tầng trung và tầng thấp \\
\hline 11 & $\mathrm{MI}$ & IR window & 8.6 & & Trạng thái mây, SO2 \\
\hline 12 & $\mathrm{O} 3$ & Ozone & 9.6 & & Hàm lượng $\mathrm{O} 3$ \\
\hline 13 & IR & \multirow{3}{*}{ IR window } & 10.4 & & Ảnh mây, thông tin nhiệt độ đỉnh mây \\
\hline 14 & $\mathrm{~L} 2$ & & 11.2 & & Ảnh mây, nhiệt độ nước biển \\
\hline 15 & 12 & & 12.4 & & Ảnh mây, nhiệt độ nước biển \\
\hline 16 & co & $\mathrm{CO}_{2} \approx$ & 13.3 & & Độ cao đỉnh mây \\
\hline
\end{tabular}

Hình 1. Các kênh phổ của vệ tinh Himawari.

Hiện nay trên thế giới đã có nhiều nghiên cứu phân tích, ứng dụng dữ liệu vệ tinh Himawari-8 đã được thực hiện, điển hình là các nghiên cứu: (1) [1] đã nghiên cứu, ứng dụng thuật toán mặt nạ mây (Cloud Mask Product) để đưa ra các sản phẩm pha, loại và độ cao đỉnh mây; (2) Trung tâm Vệ tinh Khí tượng (MSC) thuộc Cơ quan Khí tượng Nhật Bản (JMA) đã phát triển và cung cấp một sản phẩm có tên là HCAI (High-resolution Cloud Analysis Information), bao gồm năm yếu tố: mặt nạ mây, mặt nạ băng tuyết, loại mây, độ cao đỉnh mây và thông tin kiểm soát chất lượng [2]; (3) Năm 2016, [3] đã giới thiệu tài liệu trình bày các thuật toán cơ bản trong việc xây dựng sản phẩm xác định độ cao đỉnh mây, độ bao phủ mây, dạng/lọai mây, thử nghiệm cho ra kết quả tính toán nhiệt độ đỉnh mây, độ cao đỉnh mây, độ che phủ mây, loại mây với kết quả tốt; (4) sản phẩm mưa vệ tinh GSMaP (Global Satellite Mapping Precipitation) được cơ quan Nghiên cứu Vũ trụ Nhật Bản (JAXA-Japan Aerospace Exploration Agency) phát triển, cung cấp một sản phẩm mưa toàn cầu với độ phân giải cao theo không gian và theo thời gian [4]; (5) [5] đã nghiên cứu để thử nghiệm so sánh các phương pháp ước tính lượng mưa dựa trên dữ liệu Himawari-8, một số phương pháp ước tính lượng mưa được thử nghiệm trong nghiên cứu này là $\mathrm{AE}, \mathrm{CST}$, CSTM, IMSRA. Nonlinear Relation và Nonlinear Inversion, dựa trên kết quả phân tích định lượng, người ta biết rằng IMSRA là phương pháp tốt nhất có thể được áp dụng để ước tính lượng mưa trong thời kỳ mùa đông của Muarateweh và Palangka Raya (Indonesia); (6) Trong hội thảo về dự báo tức thời ổ dông đối lưu, Dixon [6] đã giới thiệu phương pháp xác định các ổ mây dông và phương pháp ngoại suy hướng và tốc độ di chuyển của chúng, được sử dụng cho các nước như: Hoa Kì, Mexico, Đài Loan, Brazil, Úc...

Trong nước, có nhiều nghiên cứu trong lĩnh vực xử lý dữ liệu vệ tinh điển hình như: (1) Năm 2018 [7] đã nghiên cứu xây dựng bản đồ mây từ thông tin vệ tinh phục vụ nghiệp vụ dự báo mưa, dông. Nghiên cứu sử dụng các thông tin nhiệt bức xạ tại các dải phổ hồng ngoại nhiệt và hơi nước từ vệ tinh khí tượng địa tĩnh MTSAT-2 và Himawari-8 kết hợp với số liệu quan trắc từ các trạm quan trắc bề mặt trong nước và khu vực trong những năm gần đây để xây dựng phương pháp phân loại mây; (2) Năm 2010 [8] đã có báo cáo về nghiên cứu phương 
pháp xác định lượng mưa trên cơ sở ảnh mây vệ tinh địa tĩnh MTSAT cho khu vực Việt Nam, phương pháp dùng mạng thần kinh nhân tạo (ANN) để xác định lượng mưa cho khu vực Việt Nam từ thông tin bức xạ của vệ tinh khí tượng Một số kết quả ban đầu cho thấy phương pháp này nhìn chung tăng cường độ chính xác của việc ước lượng mưa từ thông tin vệ tinh.

Với đặc điểm địa lý và khí hậu, trên khu vực ĐBSC mưa-dông chủ yếu là do hệ thống mây đối lưu gây ra, nên nghiên cứu này sẽ tập chung giới thiệu phương pháp và công cụ xử lý dữ liệu vệ tinh Himawari-8 để tạo ra các sản phẩm phân loại mây, ước lượng lượng mưa, tính toán sự di chuyển của các khối mây đối lưu, từ đó đưa ra các dự báo, cảnh báo mưa-dông kịp thời và hiệu quả cho các khu vực thuộc ĐBSCL.

\section{Phương pháp nghiên cứu}

\subsection{Khu vực nghiên cưu và nguồn số liệu}

Khu vực nghiên cứu là vùng ĐBSCL gồm 13 tỉnh thành: Long An, Tiền Giang, Đồng Tháp, Vĩnh Long, Trà Vinh, Hậu Giang, Sóc Trăng, Bến Tre, An Giang, Kiên Giang, Bạc Liêu, Cà Mau và thành phố Cần Thơ.

Nguồn số liệu vệ tinh Himawari-8 sử dụng trong nghiên cứu này được thu nhận từ mạng đồng bộ dữ liệu của Tổng cục KTTV với tần suất 10 phút/lần với số lượng kênh đầy đủ là 16 kênh và độ phân giải không gian cao nhất $(0,5-1 \mathrm{~km}$ đối với kênh thị phổ, $1-2 \mathrm{~km}$ đối với kênh cận hồng ngoại và $2 \mathrm{~km}$ đối với hồng ngoại), thời gian trễ do xử lý và hệ thống đồng bộ vào khoảng $10-15$ phút.

\subsection{Phương pháp phân loại mây}

Năm 2016, [2] đã giới thiệu về kỹ thuật tính toán xác định phân loại mây từ số liệu vệ tinh Himawari-8. Phương pháp này gọi là HCAI. Sản phẩm đầu ra của phương pháp là những thông tin về mây như sau:

- Độ che phủ của mây (bao gồm cả bụi): vùng có mây và không có mây.

- Độ che phủ của băng tuyết: xác định vùng có hay không có băng tuyết.

- Loại mây xác định được chia thành quang mây, mây $\mathrm{Cb}$, mây tầng cao $\mathrm{CH}$, mây tầng trung $\mathrm{CM}$, mây $\mathrm{Cu}$, mây $\mathrm{Sc}$, mây $\mathrm{St}$ và sương mù $(\mathrm{St} / \mathrm{fog})$ và mây dày đặc.

- Độ cao đỉnh mây tính cho từng khoảng $100 \mathrm{~m}$.

- Thông tin đánh giá chất lượng.

Quy trình phân loại mây được thực hiện theo các bước như minh họa trong hình 2 . Từ số liệu đầu vào là ảnh mây vệ tinh và sản phẩm mô phỏng từ mô hình số trị, các tính toán đầu tiên áp dụng để xác định vùng có mây che phủ, có băng tuyết che phủ và vùng quang mây. Không giống như quan trắc mây từ các trạm quan trắc, trong các tính toán từ vệ tinh chỉ xác định theo nhóm các loại mây như sau:

- Nhóm mây đối lưu $\mathrm{Cu}, \mathrm{Cb}$.

- Nhóm sương mù và mây St.

- Nhóm các mây tầng cao $\mathrm{CH}$.

- Nhóm các mây tầng trung CM.

- Mây tầng thấp Sc

- Mây dày đặc.

Đối với thông tin về loại mây được xác định như các loại mây tế quang, thấu quang và cấu tạo bởi các thành phần rời rạc. Loại mây thấu quang và tế quang được phân thành 7 mức dựa trên nhiệt độ phát xạ thu được tại kênh $11,2 \mu \mathrm{m}$ và mẫu hình mây gồm những phần tử rời rạc cho mỗi mực.

Mỗi mực được tính toán dựa trên việc so sánh giữa $\mathrm{T}(11.2)$ tức nhiệt độ phát xạ thu được tại kênh 11,2 $\mu \mathrm{m}$ và Tplev(11.2) tức là nhiệt độ lan truyền bức xạ tại bước sóng $11,2 \mu \mathrm{m}$ của đám mây tương ứng với từng mực khí áp quan sát trên $\mathrm{AHI}$ và tính toán dựa trên sản phẩm lan truyền bức xạ của mô hình GSM. 
Mực 1: mây rất cao

Mực 2: mây cao

$$
\mathrm{T}(11.2)<0.5 \times \mathrm{T}_{400 h \mathrm{~Pa}}(11.2)+0.5 \times \mathrm{T}_{200 h \mathrm{~Pa}}(11.2)
$$

$$
0.5 \times \mathrm{T}_{400 \mathrm{hPa}}(11.2)+0.5 \times \mathrm{T}_{200 \mathrm{hPa}}(11.2) \leq \mathrm{T}(11.2)<\mathrm{T}_{400 \mathrm{hPa}}(11.2)
$$

Mực 3: mây khá cao và mây tầng trung

$$
\mathrm{T}_{400 \mathrm{hPa}}(11.2) \leq \mathrm{T}(11.2)<0.5 \times \mathrm{T}_{400 \mathrm{hPa}}(11.2)+0.5 \times \mathrm{T}_{600 \mathrm{hPa}}(11.2)
$$

Mực 4: Mây khá thấp và mây tầng trung

Mực 5: Mây thấp

$$
0.5 \times \mathrm{T}_{400 \mathrm{hPa}}(11.2)+0.5 \times \mathrm{T}_{600 \mathrm{hPa}}(11.2) \leq \mathrm{T}(11.2)<\mathrm{T}_{600 \mathrm{hPa}}(11.2)
$$

Mực 6: Mây rất thấp

$$
\mathrm{T}_{600 \mathrm{hPa}}(11.2) \leq \mathrm{T}(11.2)<0.5 \times \mathrm{T}_{600 \mathrm{hPa}}(11.2)+0.5 \times \mathrm{T}_{\text {surface }}(11.2)
$$

Mực 7: Mây đặc biệt thấp

$$
0.5 \times \mathrm{T}_{600 \mathrm{hPa}}(11.2)+0.5 \times \mathrm{T}_{\text {surface }}(11.2) \leq \mathrm{T}(11.2)<\mathrm{T}_{\text {surface }}(11.2)
$$

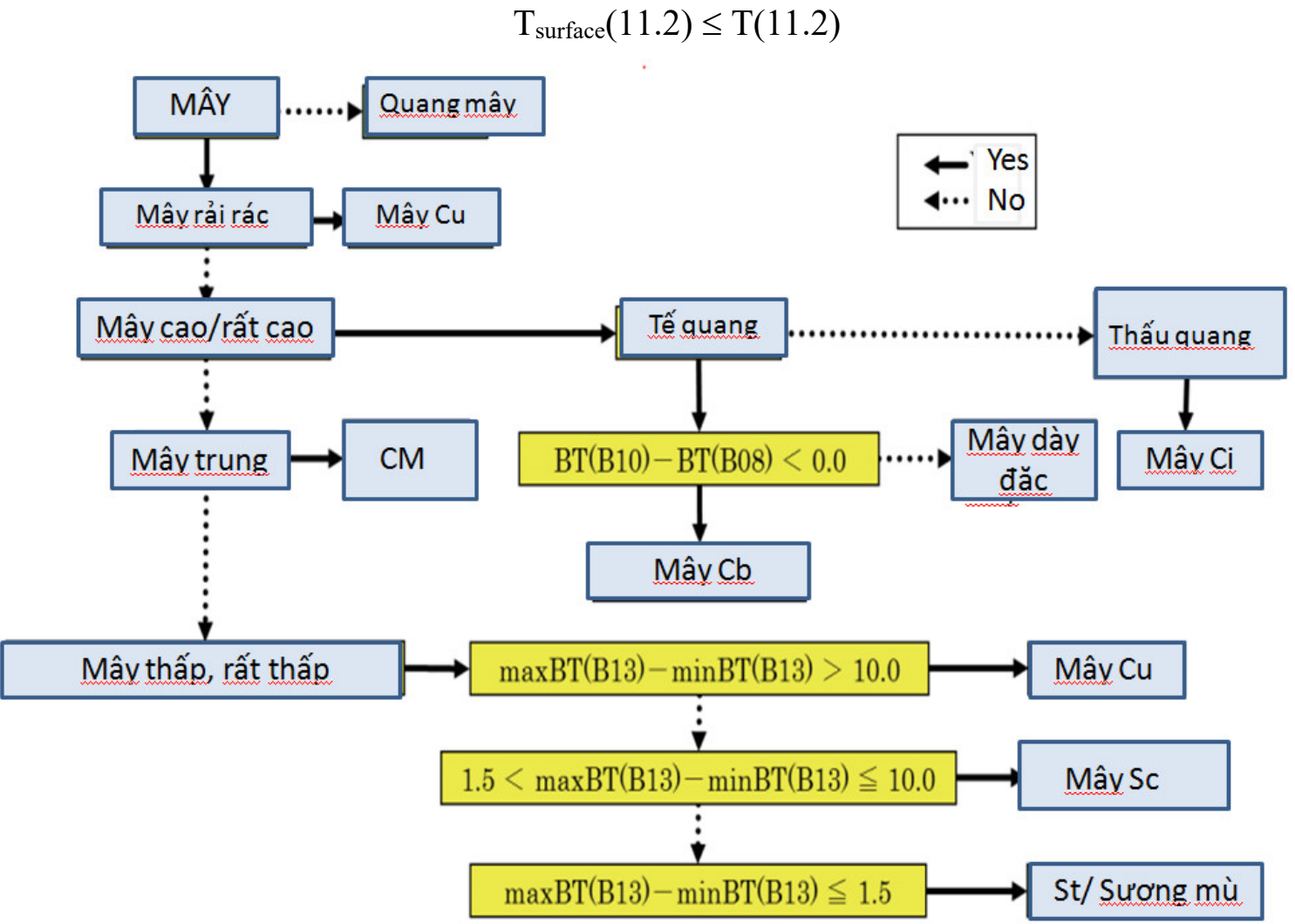

Hình 2. Quy trình phân loại mây.

\subsection{Phương pháp xác định nhiệt độ và độ cao đỉnh mây}

Trong nghiên cứu này nhóm tác giả lựa chọn một phương pháp được công bố năm 2016 [1] đã đưa ra các thuật toán tính toán ra sản phẩm thứ cấp về mây gồm độ che phủ của mây, loại mây, pha của mây và độ cao đỉnh mây. Phương pháp này đang được sử dụng nghiệp vụ tại cơ quan khí tượng Nhật (JMA).

\subsubsection{Quy trình tính toán}

Đối với nhiệt độ đỉnh mây, các tính toán được tính theo các nguyên tắc dựa trên phân loại mây. Với mây rất thấp, mây thấp và mây trung bình được tính toán dựa trên nhiệt độ phát xạ của kênh $11,2 \mu \mathrm{m}$. Đối với mây cao và dày, sử dụng tỉ lệ bức xạ giữa các kênh. 


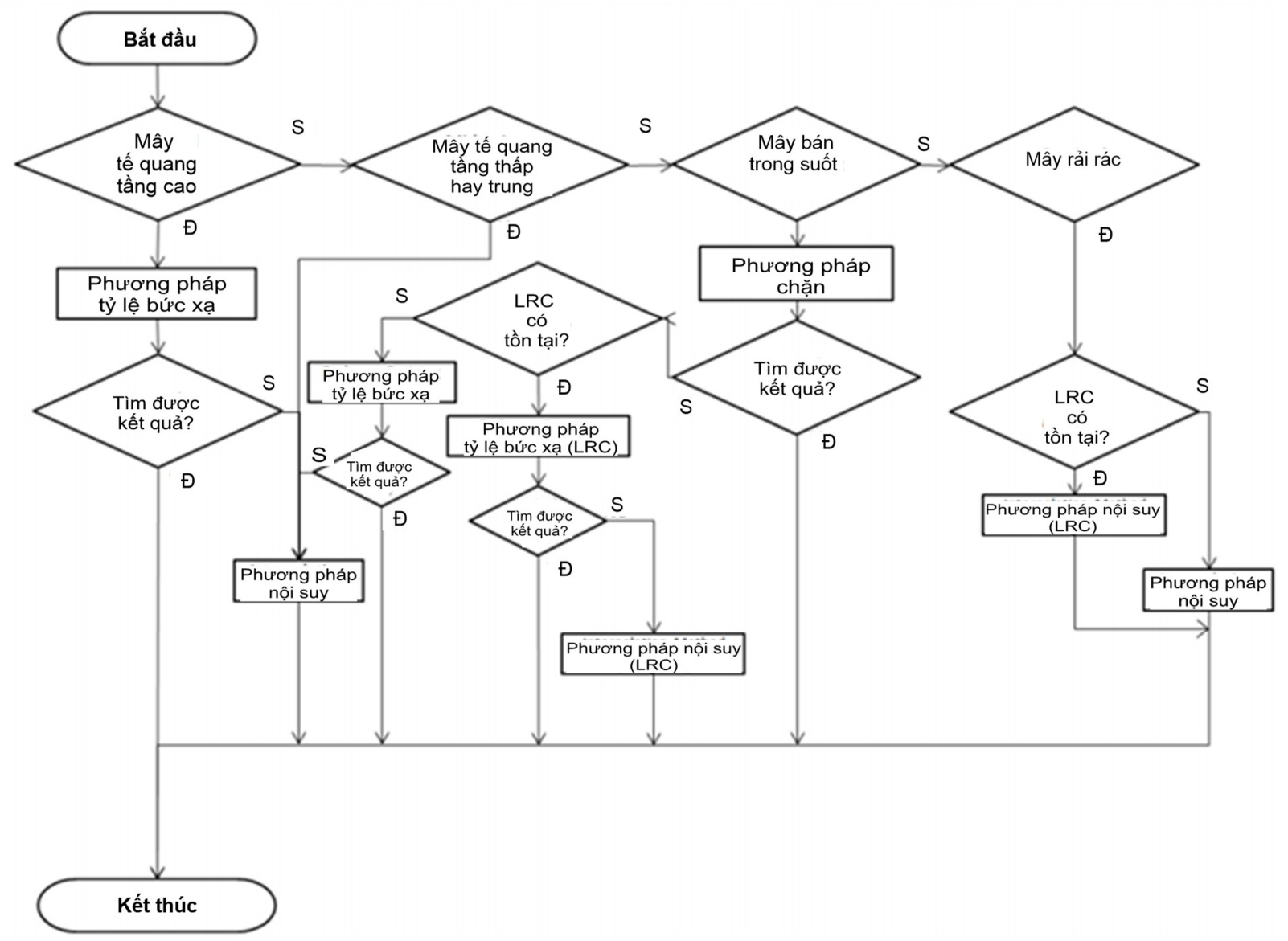

Hình 3. Quy trình xác định nhiệt độ và độ cao đỉnh mây.

Để tính toán độ cao đỉnh mây cần sử dụng cả 3 phương pháp sau:

- Phương pháp nội suy;

- Phương pháp tỉ lệ bức xạ;

- Phương pháp chặn.

Các bước tính toán được thực hiện theo sơ đồ trên hình 4 . Tại đây khi bắt đầu tính toán dựa trên phân loại mây. Trong phân loại chia là một lựa chọn sau:

- Mây cao tế quang (High level Opaque Cloud);

- Mây thấp và mây mực giữa tế quang (Mid or low Level Opaque cloud);

- Mây thấu quang (Semi-transparent cloud);

- Mây rời rạc (Fractional cloud).

Tương tự với mỗi loại mây, thực hành tính toán theo từng phương pháp như trên sơ đồ đã trình bày. Đầu ra của chu trình sẽ gồm:

- Độ cao đỉnh mây: tính bằng mét.

- Nhiệt độ đỉnh mây: tính bằng độ $\mathrm{K}$.

- Áp suất đỉnh mây: tính bằng hPa.

\subsection{Xác định vùng mây đối lưu (CCI)}

Sản phẩm CCI được tính toán được phân thành 3 loại:

- Vùng mây $\mathrm{Cu}$ phát triển nhanh RDCA;

- Vùng mây $\mathrm{Cb}$;

- Vùng hình đe ở đỉnh mây $\mathrm{Cb}$ tỏa ra phía dưới có các mây tầng trung và tầng thấp không xác định MLUA.

Bộ công cụ tiếp theo được thiết lập để tính toán phân biệt các vùng mây dựa trên 6 kênh phổ ở trên. Các bước tính toán được thực hiện theo sơ đồ sau: 


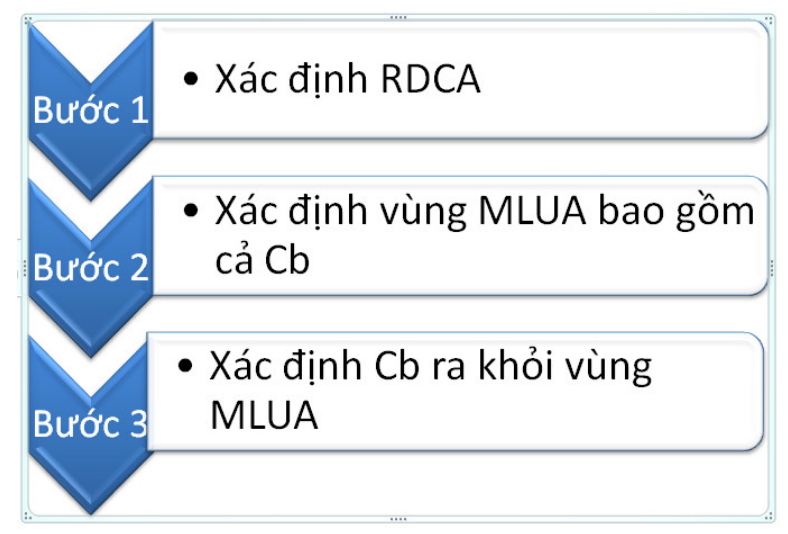

Hình 4. Trình tự tính toán xác định các vùng mây RDCA, MLUA và Cb.

Bước 1: Thao tác khoanh vùng RDCA ra khỏi vùng không mây, vùng mây thấp, mây mỏng tầng cao mô tả như trong bảng 1 .

Bảng 1. Các ngưỡng phân loại để xác định vùng RDCA.

\begin{tabular}{lll}
\hline \multicolumn{1}{c}{ Thành phần } & \multicolumn{1}{c}{ Ngưỡng } & \multicolumn{1}{c}{ Mục đích } \\
\hline BT kênh 13 & $<288.15^{\circ} \mathrm{K}$ & Lọc vùng không mây \\
Suất phản xạ kênh 3 & $>0.45$ & Lọc bỏ vùng mây mỏng và chọn vùng mây dày \\
BT kênh 13-kênh 15 & $<2.0^{\circ} \mathrm{K}$ & Lọc vùng mây mỏng tầng cao \\
\hline
\end{tabular}

Bước 2: là xác định vùng mây MLUA. Vùng mây này được xác định dựa trên nhiệt độ đỉnh mây ở kênh 13 thấp và suất phản xạ trên kênh 3 lớn để đảm bảo đây là vùng mây cao và dày. Toàn bộ vùng này được tạm coi là MLUA.

Bước thứ 3: Vùng được coi như $\mathrm{Cb}$ phải qua bước loại trừ sử dụng phương pháp chặn như sau:

(1) Trong trường hợp chênh lệch giữa $\bar{T}^{\mathrm{b}}$ và $\mathrm{Tt}<40 \mathrm{~K}$ thì phát hiện mây $\mathrm{CB}$ bị loại bỏ.

(2) Phát hiện $\mathrm{CB}$ sẽ bị loại trừ nếu tỉ lệ chu vi vùng MLUA chỉ dưới $25 \%$ so với chu vi vùng $\mathrm{CB}$.

(3) CB tan rã: Nếu xuất hiện trạng thái $\mathrm{CB}$ tan rã thì phát hiện $\mathrm{CB}$ cũng bị loại bỏ. Trạng thái $\mathrm{CB}$ tan rã căn cứ vào 3 yếu tố sau:

- Sự thay đổi của BT trên kênh 13 của các đám mây;

- Sự suy giảm của những điểm có phát xạ cao;

- Sự suy giảm của phân kỳ. 


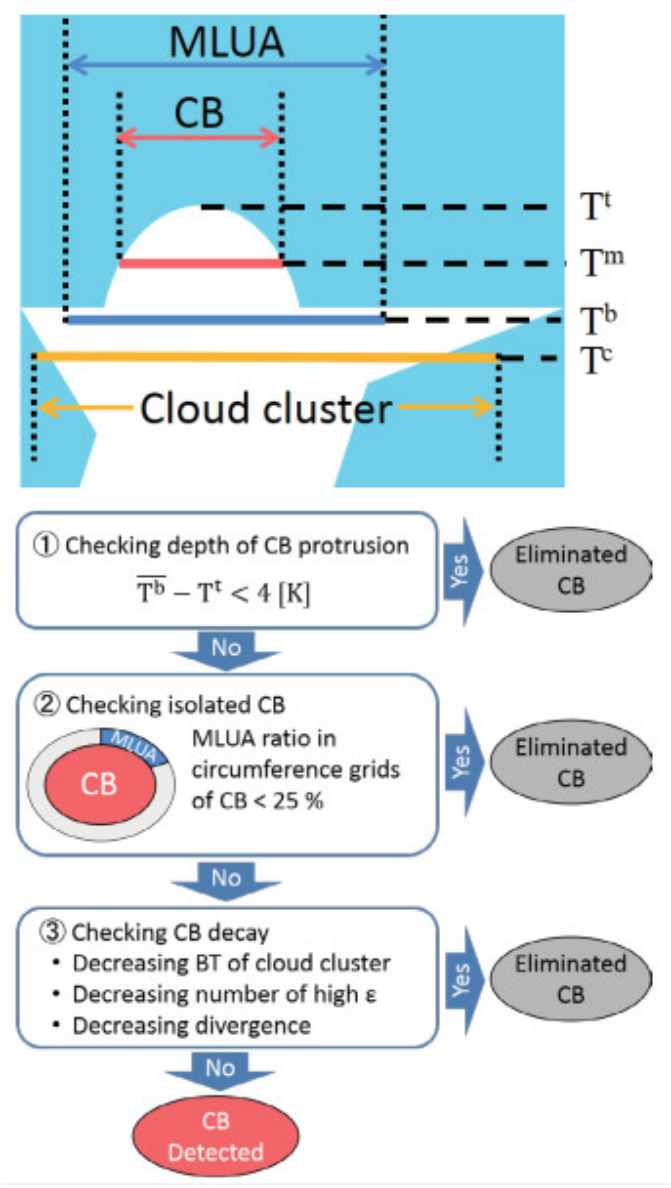

Hình 5. Mẫu hình $\mathrm{CB}$ và sơ đồ loại bỏ vùng $\mathrm{CB}$ để xác định MLUA.

\subsection{Phương pháp xác định ổ mây dông}

Đối với việc xác định vùng mây của hệ thống mây được thực hiện như sau: một đám mây được định nghĩa là một miền liên thông các điểm luới có cùng giá trị (được xác định trong phẩn phân loại mây). Bài toán đặt ra làm thế nào để tìm ra miền liên thông lớn nhất trên một ma trận. Nhìn trên hình 6 có thể xác định được 5 miền liên thông đại diện cho 5 ổ mây dông [6]. Như vậy sau khi lặp trên toàn bộ mảng hai chiều, biến đếm sẽ cho ta số lượng các miền liên thông trên đồ thị, và các điểm trên cùng một miền liên thông sẽ có giá trị mảng bằng nhau.

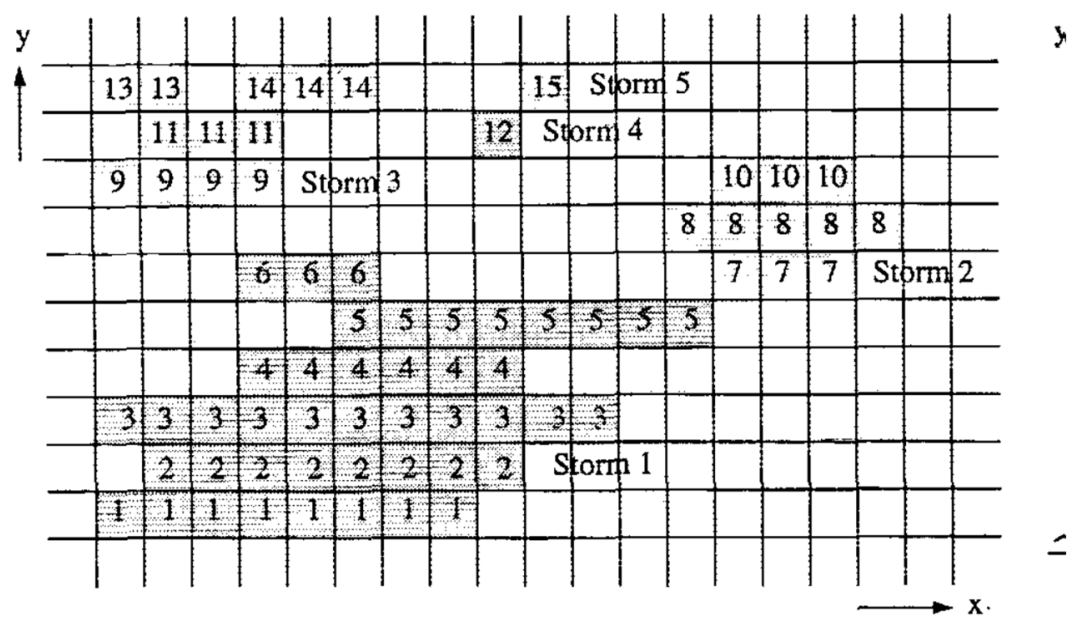

Hình 6. Thí dụ về miền liên thông xác định ổ mây dông. 


\subsection{Phương pháp ước lựng lựng mura}

Theo nghiên cứu của Trung tâm vệ tinh khí tượng của Nhật đã đưa ra phương pháp xác định lượng mưa tiềm năng cho các khu vực có mây đối lưu mạnh từ các kênh phổ của vệ tinh Himawari-8. Phương pháp này sử dụng nhiệt độ sáng của ba kênh phổ $6.2 \mu \mathrm{m}$ (T6.2), 10.4 $\mu \mathrm{m}$ (T10.4) và $12.4 \mu \mathrm{m}$ (T12.4) để chiết xuất được khu vực mây đối lưu sâu. Một số mô tả sau là thuật toán cơ bản đưa ra để phát hiện ra các đám mây đối lưu với đỉnh cao:

Nhiệt độ sáng của T6.2 là thấp hơn nhiệt độ sáng của T10.4 và T12.4 thì khi đó mây ở trạng thái phát triển và đỉnh của chúng không đạt đến tầng đối lưu;

Nhiệt độ sáng của T6.2, T10.4 và T12.4 là gần như giống nhau khi đỉnh mây đối lưu đạt đến tầng đối lưu;

Nhiệt độ sáng của T6.2 có thể cao hơn T10.4 khi đỉnh mây vượt vào đến tầng bình lưu;

Hiệu số giữa nhiệt độ sáng của T10.4 và T12.4 tăng khi mây Ci mỏng được quan sát thấy.

Phương pháp này đưa ra bước đầu tiên đó là xác định khu vực tiềm năng có mưa lớn từ việc xác định các khu vực có mây đối lưu sâu, tuy nhiên phương pháp không xác định lượng mưa là bao nhiêu. Vậy để xác định lượng mưa trung bình cho một khu vực có tiềm năng mưa lớn đó là tính toán hàm của nhiệt độ sáng của kênh phổ $10.4 \mu$ (T10.4) với phương trình:

$$
\mathrm{R}=1.183 \times 1011 \exp (-3.6382 \times 10-2 \times \mathrm{T} 0.5)
$$

Ở đây $\mathrm{R}$ là ước lượng mưa $\mathrm{mm} / \mathrm{h}$ và $\mathrm{T}$ là nhiệt độ sang của mây tại kênh hồng ngoại dải số $13(10.4 \mu \mathrm{m})$. Sơ đồ thực hiện như Hình 7.

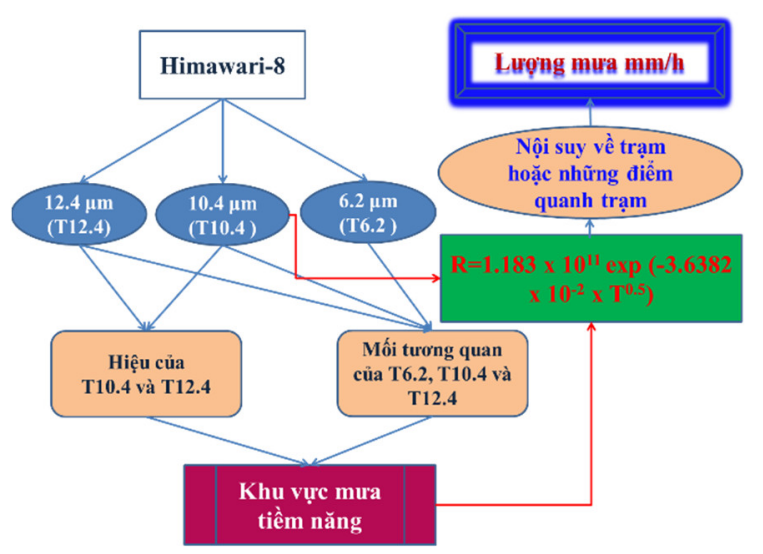

Hình 7. Sơ đồ thực hiện phương pháp xác định mưa từ tổng hợp các kênh phổ.

\subsection{Phưong pháp tính toán dịch chuyển của các ổ mây đối lưu}

Sau khi tính toán nhận dạng được CCI, một module tiếp theo được tính tới sự dịch chuyển của nó. Sự di chuyển của các đám mây và dự báo sự di chuyển của nó được tính toán từ ngoại suy quá trình di chuyển của đám mây ở thời điểm gần nhất trước đó. Hai vùng đưa vào tính tương quan dựa trên các nguyên tắc sau:

Một vùng liên quan tới các đặc điểm của mây được xác định trong ảnh $\mathrm{B}$ ta tạm gọi là vùng $\mathrm{T}$ dùng để làm mốc tính chuyển động (Hình ). Tìm kiếm trong ảnh $\mathrm{A}$ được so sánh với vị trí tương ứng của vùng $\mathrm{T}$ trong ảnh $\mathrm{B}$.

Trong Hình khu vực vùng mây có kích thước $(2 \mathrm{t}+1)$. Sang tới thời điểm hiện tại trên ảnh $\mathrm{A}$ vùng tìm kiếm có kích thước ô lưới $(2 \mathrm{~s}+1)$. Khi đó vị trí trung tâm của vùng mây được xác định có vị trí $\left(\mathrm{x}_{0}, \mathrm{y}_{0}\right)$ được tính như sau: 

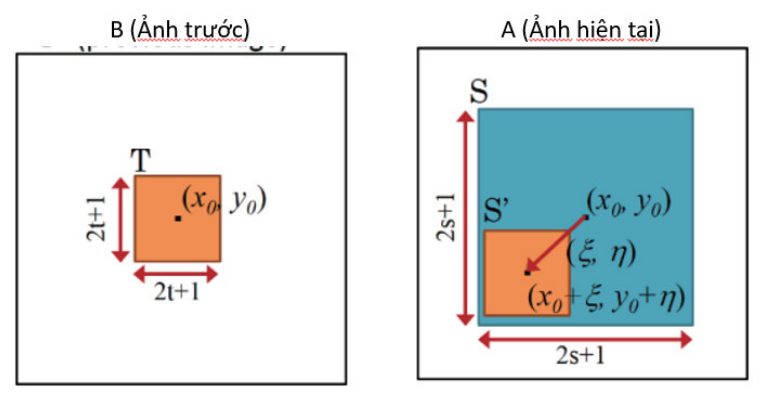

Hình 8. Vùng mẫu và vùng tìm kiếm cho quỹ đạo chuyển động của mây.

$$
\mathrm{T}(\mathrm{i}, \mathrm{j})=\mathrm{VB}(\mathrm{x} 0+\mathrm{i}, \mathrm{y} 0+\mathrm{j})-\mathrm{t} \leq \mathrm{i} \leq \mathrm{t},-\mathrm{t} \leq \mathrm{j} \leq \mathrm{t}
$$

Khu vực tìm kiếm trên ảnh $\mathrm{A}$ với vị trí tọa độ tương tự $\left(\mathrm{x}_{0}, \mathrm{y}_{0}\right)$ được tính theo công thức:

$$
\mathrm{S}(\xi, \eta)=\operatorname{VA}((\mathrm{x} 0+\xi, \mathrm{y} 0+\eta)-\mathrm{s} \leq \xi \leq \mathrm{s},-\mathrm{s} \leq \eta \leq \mathrm{s}
$$

Vùng mây di chuyển tới khu vực $S$ ' có tâm ở tọa độ $(\zeta, \eta)$ trong vùng tìm kiếm $S$ ở ảnh $A$ :

$\mathrm{S}^{\prime}(\xi, \eta)(\mathrm{i}, \mathrm{j})=\mathrm{S}(\xi+\mathrm{i}, \eta+\mathrm{j})-\mathrm{t} \leq \mathrm{i} \leq \mathrm{t},-\mathrm{t} \leq \mathrm{j} \leq \mathrm{t}$

Tương quan ngoại suy giữa $\mathrm{C}(\zeta, \eta)$ giữa $\mathrm{T}$ và $\mathrm{S}$ ' được tính như sau:

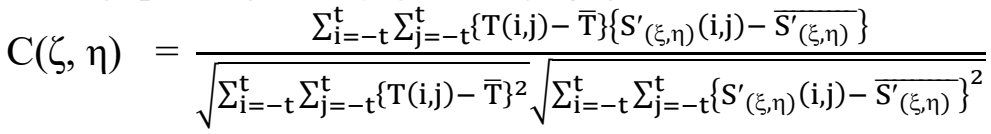

$$
\begin{aligned}
& \overline{\mathrm{T}}=\frac{1}{(2 \mathrm{t}+1)^{2}} \sum_{\mathrm{i}=-\mathrm{t}}^{\mathrm{t}} \sum_{j=-\mathrm{t}}^{\mathrm{t}} \mathrm{T}(\mathrm{i}, \mathrm{j}) \\
& \overline{S^{\prime}(\xi, \eta)}=\frac{1}{(2 t+1)^{2}} \sum_{i=-t}^{t} \sum_{j=-t}^{t} S_{(\xi, \eta)}^{\prime}(i, j)
\end{aligned}
$$

Điểm cực đại $(\zeta, \eta)$ của $C(\zeta, \eta)$ được tính là chuyển động của các vùng mây tại lưới $(\mathrm{x} 0$, y0) trên ảnh $\mathrm{B}$ và lưới vị trí tương ứng trên ảnh $\mathrm{A}$.

\section{Kết quả và thảo luận}

Các phương pháp và thuật toán được hiện tực bằng các công cụ phần mềm máy tính và được tích hợp trong một phần mềm duy nhất, thực hiện từ khâu thu nhập, giải mã số liệu vệ tinh Himawari đến kết xuất và chuyển phát sản phẩm. Công cụ phần mềm đã được triển khai ứng dụng trong công tác dự báo, cảnh báo mưa-dông cho khu vực ĐBSCL của Đài KTTV Nam Bộ. Dưới đây là một số kết quả và sản phẩm của công cụ phần mềm. Số liệu vệ tinh từ 0800UTC đến 0900UTC ngày 31/07/2020.

\subsection{Hiển thị số liệu các kênh phổ ảnh mây}

Kết quả đọc, giải mã số liệu các kênh phổ, thực hiện hiển thị chồng lớp với bản đồ nền GIS khu vực, các kênh phổ được thể hiện nhiệt độ hoạt độ sáng bằng bảng màu. Hình 9 hiện thị phân bố nhiệt kênh 15 (I2) và hình 10 hiển thị phân bố độ sáng kênh VIS (3) lúc 8h50 UTC. 


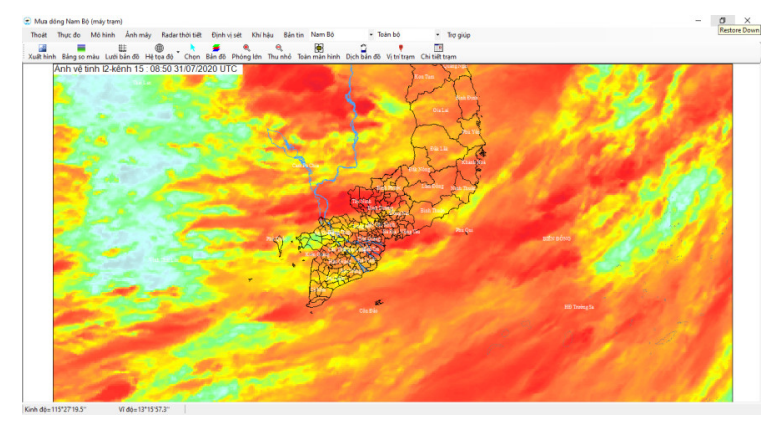

Hình 9. Phân bố nhiệt kênh 13 lúc 8h50UTC.

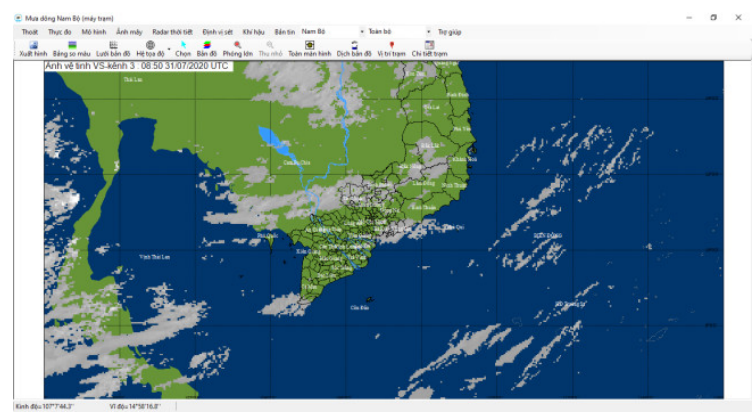

Hình 10. Phân bố độ sáng kênh VS lúc 8h50UTC.

\subsection{Phân tích nhận dạng loại mây}

Thực hiện các giải thuật và các bước tính toán theo phương pháp HCAI, kết quả phân loại mây lúc 0850UTC được hiển thị trên bản đồ hình 11, với các loại mây được phân tách: $\mathrm{Cb}, \mathrm{Cu}, \mathrm{Sc}, \mathrm{St}$ và $\mathrm{Ci}$. Kết quả trên khá tương đồng với kết quả tính toán của JMA trên trang JAXA Himawari Monitor (hình 12), nhất là các vùng mây đối lưu $\mathrm{Cb}$ (màu đỏ trên hình 11 và màu xanh trên hình 12).

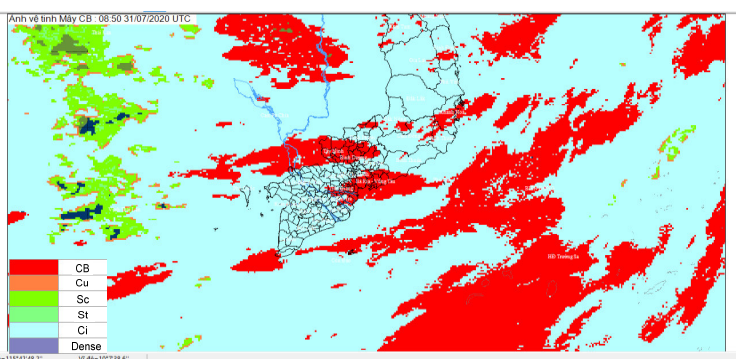

Hình 11. Kết quả phân loại mây lúc 8h50UTC.

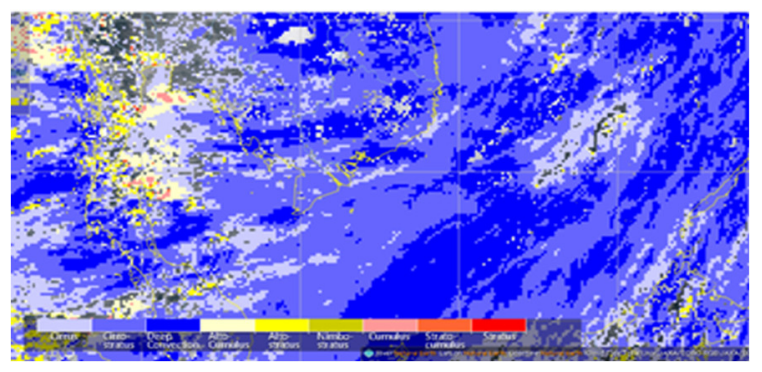

Hình 12. Kết quả phân loại mây lúc 0850UTC của JMA( website JAXA Himawari Monitor).

\subsection{Xác định vùng có thể sinh mura-dông}

Thực hiện các giải thuật và các bước tính toán theo phương pháp CCI, kết quả phân loại được các khối mây có khả năng sinh mưa và gây dông lúc 0850UTC được hiển thị trên bản đồ hình 13, các khu vực có màu đỏ được cảnh báo là sẽ gây mưa dông. Lượng mưa ước lượng từ các khối mây này sẽ được xử lý trong mục sau.

\section{4 Định danh các vùng mây đối lưu (CB)}

Sau khi phân loại mây, công cụ phần mềm thực hiện giải thuật tính toán, định danh các ổ mây dông, kêt quả được thể hiện trong hình 14 với các ổ mây dông (phân biệt bằng màu khác nhau) lúc 0850UTC. Ảp dụng phép ngoại suy, xác định được hướng và tốc độ di chuyển của các đám mây dông, từ đó đưa ra các cảnh báo mưa-dông cho các vùng địa lý trong 1-3h tới.

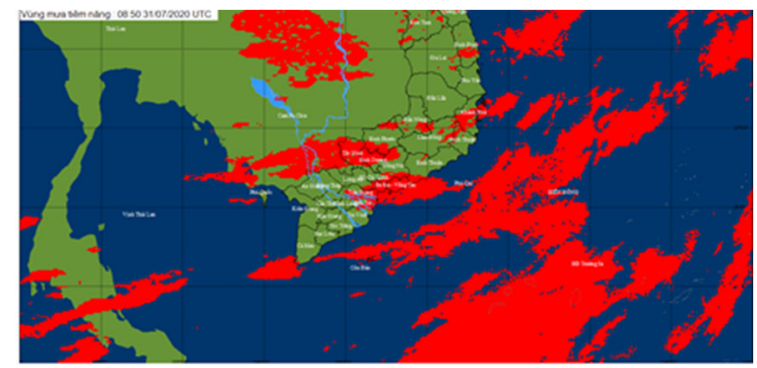

Hình 13. Kết quả phân vùng mây có khả năng gây ra mưa-dông lúc 8h50UTC.

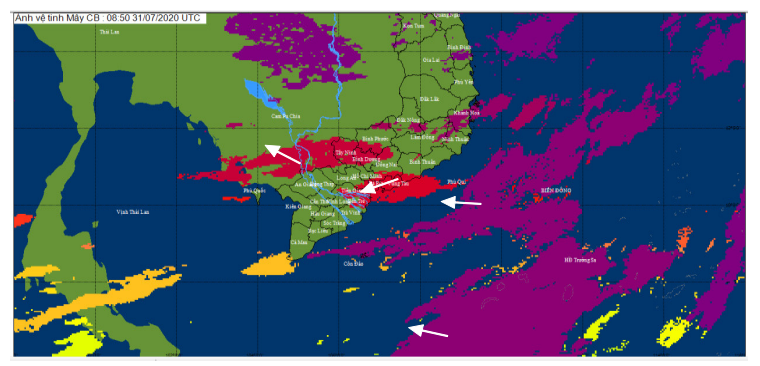

Hình 14. Kết quả xác định các ổ mây dông và hướng di chuyển. 


\subsection{Uớc lượng luợng mura}

Bước tiếp theo trong hệ thống cảnh báo mưa-dông là tính toán, ước lượng lượng mưa có thể sinh ra từ các đám mây dông. Hình 15 trình bày kết quả ước lượng mưa trong $1 \mathrm{~h}$ từ 0800UTC đến 0900UTC trên khu vực ĐBSCL. Khu vực mưa diện rộng và lượng mưa lớn dược tính toán xác định ở vùng Bình Phước và Tây Ninh, ngoài ra còn rải rác có mưa ở khu vực ven biển Vũng Tàu-TPHCM-Bến Tre. So sánh với kết quả thống kê lượng mưa thực đo cùng thời gian (hình 16 ), chúng ta thấy khu vực mưa diện rộng và lượng mưa nhiều là khu vực Bình Phước-Tây Ninh, vùng ven Đồng Nai, Bình Dương và các vùng ven biển Vũng Tàu-TPHCM-Bến Tre lượng mưa không nhiều. Điều này cho thấy sự tương đồng giữa lượng mưa tính toán từ số liệu vệ tinh và lượng mưa thực đo.
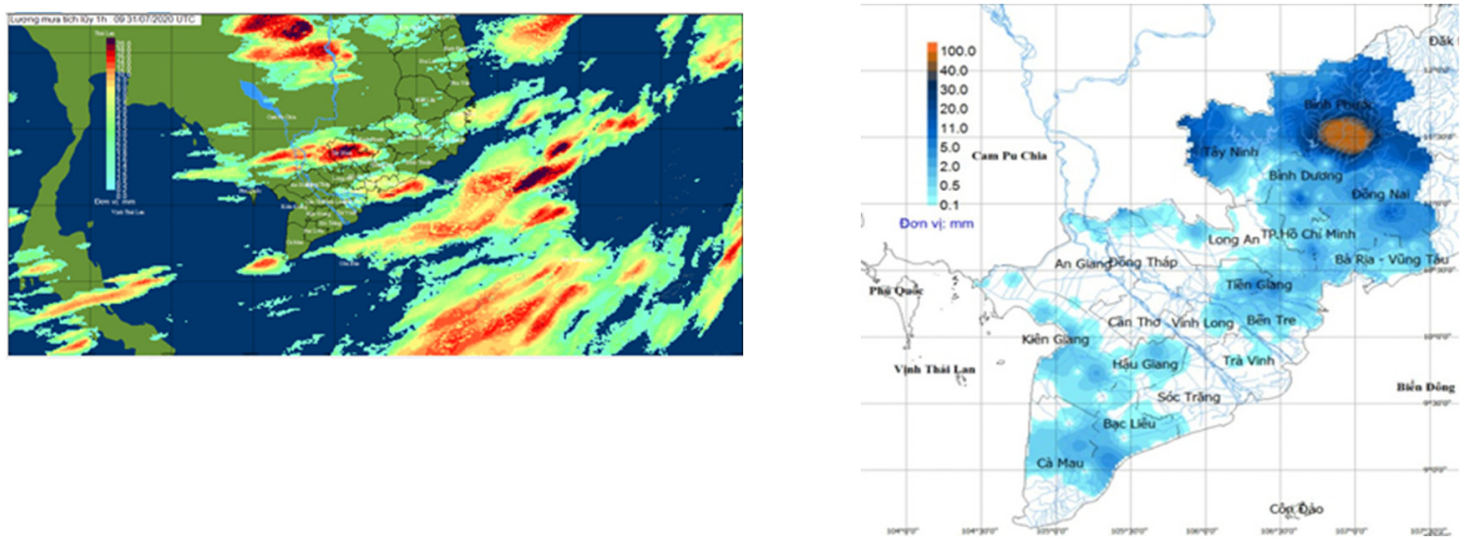

Hình 15. Kết quả ước lượng lượng mưa trong $1 \mathrm{~h}$ từ

Hình 16. Lượng mưa thực đo trong $1 \mathrm{~h}$ từ 0800UTC 0800UTC đến 0900UTC. đến 0900UTC.

Các kết quả tính toán của công cụ phần mềm được chồng lớp và tính toán không gian cho các khu vực địa lý, cụ thể tính toán và cảnh báo đến cấp quận-huyện của các tỉnh thuộc ĐBSCL. Hình thức cung cấp thông tin gồm có:

Hiển thị trực quan trên bản đồ GIS: các khu vực được cảnh báo mưa-dông sẽ hiển thị với màu cam trên bản đồ (Hình 17).

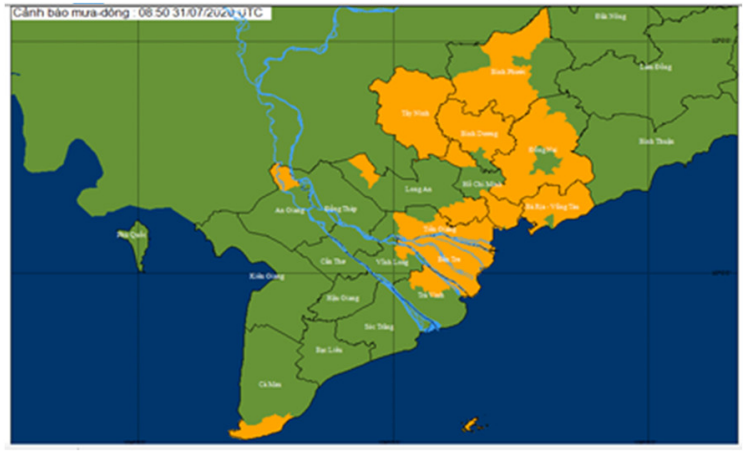

Hình 17. Cảnh báo trực quan các khu vực có mưa dông trong vùng ĐBSCL lúc 8h50UTC.

\begin{tabular}{|c|c|c|c|c|c|c|}
\hline Quận-Huyện & $15: 0031 / 071$ & $1 / 0$ & $1 / 6$ & $1 / 07$ & $1 / 07$ & $1 / 07$ \\
\hline Huyện An Phú & 0 & 0 & 0 & 0.9 & 1.1 & 2.1 \\
\hline TP. Chåu Dớc & 0 & 0 & 0 & 0 & 0 & 0 \\
\hline Huyện Châu Phú & 0 & 0 & 0 & 0 & 0 & 0 \\
\hline Huyện Chåu Thành & 0 & 0 & 0 & 0 & 0 & 0 \\
\hline Huyện Chợ Mới & 0 & 0 & 0 & 0 & 0 & 0 \\
\hline TP. Long Xuyên & 0 & 0 & 0 & 0 & 0 & 0 \\
\hline Huyện Phú Tân & 0 & 0 & 0 & 0 & 0 & 0 \\
\hline Thị xă Tân Châu & 0 & 0 & 0 & 0 & 0.6 & 1.8 \\
\hline Huyện Thoại Son & 0 & 0 & 0 & 0 & 0 & 0 \\
\hline Huyện Tịnh Biên & 0 & 0 & 0 & 0 & 0 & 0 \\
\hline Huyện Tri To̊n & 0 & 0 & 0 & 0 & 0 & 0 \\
\hline
\end{tabular}

Hình 18. Định dạng tập tin cảnh báo mưa-dông cho các tỉnh.

Kết xuất ra các tập tin để chuyển phát, mỗi tỉnh sẽ được kết xuất 01 tập tin dạng Excel trong đó các quận-huyện là hàng, cột là ngày-giờ cảnh báo mưa dông. Trong hình 18 là nội dung tập tin cảnh báo mưa-dông cho tỉnh An Giang, trong đó lúc 15 h30 đến 15 h50 cảnh báo khu vực huyện An Phú và Thị xã Tân Châu sẽ có mưa-dông với cường độ không lớn.

\section{Kết luận}

Việc xây dựng công cụ nhận dạng, xác định mây dông cũng như sự di chuyển của các đám mây dông sẽ nâng cao hiệu quả công tác cảnh báo dông-sét, mưa tại khu vực Nam Bô. 
Việc xây dựng công cụ tính toán ước lượng lượng mưa từ số liệu ảnh mây vệ tinh góp phần tăng hiệu quả công tác dự báo mưa, lấp đầy thông tin quan trắc mưa, phục vụ hiệu quả công tác chống ngập tại các đồ thị.

Cần phát triển ứng dụng trên điện thoại thông minh để theo dõi, cảnh báo kịp thời mưa dông cho từng thuê bao di động khi có nhu cầu.

Lời cảm ơn: Nhóm tác giả xin chân thành cảm ơn đề tài "Nghiên cứu xây dựng bộ công cụ dự báo, cảnh báo sớm mưa, lũ, dông khu vực đồng bằng sông Cửu Long" đã hỗ trợ về số liệu vệ tinh Himawari và phương pháp xây dựng công cụ nhận dạng, phân tích và xử lý số liệu vệ tinh cũng như tạo điều kiện để nhóm tác giả trình bày những kết quả nghiên cứu của mình.

Lời cam đoan: Tập thể tác giả cam đoan bài báo này là công trình nghiên cứu của tập thể tác giả, chưa được công bố ở đâu, không được sao chép từ những nghiên cứu trước đây; không có sự tranh chấp lợi ích trong nhóm tác giả.

\section{Tài liệu tham khảo}

1. Takahito, I.; Ryo, Y. Algorithm Theoretical Basis for Himawari-8 Cloud Mask Product. Meteorological Satellite Center Technical Note 2016, 61, pp. 16. Avaliable online: http://www.data.jma.go.jp/mscweb/technotes/msctechrep61-1.pdf

2. Hiroshi, S.; Takahit, I.; Kouki, M. High-resolution Cloud Analysis Information derived from Himawari-8 data. Meteorological satallite Center Technical Note 2016, 61, 43-51. Avaliable online: http://www.data.jma.go.jp/mscweb/technotes/msctechrep61-4.pdf

3. Kouki, M.; Hiroshi, S.; Ryo, Y.; Toshiharu, I. Algorithm Theoretical Basis Document for Cloud Top Height Product. Meteorological Satellite Center Technical Note 2016, 61, pp. 118. Avaliable online: http://www.nwcsaf.org/documents/20182/30662/NWC-CDOP2-GEO-MFL-SCIATBD-Cloud_v1.1.pdf/a5bb6eca-871b-4707-9c76-e0be09915d94

4. Ushio, T.; Sasashige, K.; Kubota, T.; Shige, S.; Okamoto, K.; Aonashi, K.; Inoue, T.; Takahashi, N.; Iguchi, T.; Kachi, M.; Oki, R. A Kalman filter approach to the global satellite mapping of precipitation (GSMaP) from combined passive microwave and infrared radiometric data. J. Meteorolog. Soc. Jpn. 2009, 87A, 137-151.

5. Alfuadi, N.; Agie Wandala, A. Comparative test of several rainfall estimation methods using Himawari-8 data. Inter. J. Remote Sens. Earth Sci. 2016, 13, 95-104.

6. Dixon, M.; Wiener, G. TITAN: Thunderstorm Identification, Tracking, Analysis, and Nowcasting A Radar-based Methodology. J. Atmos. Oceanic Technol. 1993, 10, 785-797.

7. Thư, N.V. Nghiên cứu xây dựng bản đồ mây từ thông tin vệ tinh phục vụ nghiệp vụ dự báo mưa, dông. Đề tài Nghiên cứu khoa học cấp Bộ, 2018.

8. Thư, N.V. Nghiên cứu phương pháp xác định lượng mưa trên cơ sở ảnh mây vệ tỉnh địa tĩnh MTSAT cho khu vực Việt Nam. Đề tài Nghiên cứu khoa học cấp Bộ, 2010.

\section{The application of himawari satellite data in forecast and warning of rain and thunderstorm}

\section{Tran Thanh Cong ${ }^{1}$, Le Ngoc Quyen ${ }^{1}$, Nguyen Minh Giam¹, Le Dinh Quyet ${ }^{1}$}

${ }^{1}$ Southern Region Hydrometeorological Center; congtt@gmail.com; quyentccb@gmail.com; nmg@kttvnb.vn; quyet.le74@gmail.com

\footnotetext{
Abstract: Himawari 8 satellite is the latest generation of satellites from Japan, including 16 spectral bands. Spectral bands analysis brings a lot of information to serve the analysis, forecasting and warning of rain-thunderstorms. This article presents the results of research
} 
on building cloud image analysis tools to support thunderstorm warning and forecasting for the Mekong River Delta (Mekong Delta). Utilities are integrated in the tool using 16 spectral bands of Himawari satellite images to analyze and calculate: cloud classification $(\mathrm{Ci}, \mathrm{Sc}, \mathrm{St}, \mathrm{Cu}, \mathrm{Cb} .$.$) , determine temperature and cloud top height, determine \mathrm{Cb}$ cloud areas, identify cloud areas capable of generating rain, calculate the movement of cloud masses $\mathrm{Cb}$. The tool also calculates analytical and forecast data for geographic regions (administrative units), and provides the fastest and most efficient way to deliver alerts and forecast information.

Keywords: Satellite; Rain; Thunderstorms; Himawari; Forecast; Warnings. 